\title{
RUA PIRES DE ALMEIDA: OBSERVAÇÃO INCORPORADA DE UM LUGAR PÚBLICO PARTICULAR
}

\author{
RUA PIRES DE ALMEIDA: PERFORMATION EVALUATION OF AN URBAN PUBLIC SPACE
}

\author{
ALCANTARA, Denise de \\ Arquiteta, doutoranda PROARQ-FAU-UFRJ.E-mail: deal.rlk@terra.com.br
}

RHEINGANTZ, Paulo Afonso

Arquiteto, Professor Adjunto PROARQ-FAU-UFRJ. E-mail: par@ufri.br

\section{BARBOSA, Alexandre}

Estudante, bolsista de Iniciação Científica FAU-UFRJ. E-mail: alexluiz7@hotmail.com

LAUREANO, Aline

Estudante, estagiária, FAU-UFRJ. E-mail: alinerita@ig.com.br

AMORIM, Flávia

Arquiteta mestranda PROARQ-FAU-UFRJ. E-mail: flaviamorim@gmail.com.br

\section{RESUMO}

Este artigo é parte da pesquisa Cognição e Projeto do Lugar: aplicação do enfoque enactivo na avaliação de desempenho de lugares urbanos, e busca incorporar os conceitos de cognição enactiva proposto por Varela, Thompson e Rosch e de empatia, proposto por Thompson, ao trabalho de Tuan, de Norberg-Schulz, Lynch, Cullen em uma observação incorporada realizada em um lugar de reconhecida qualidade no Rio de Janeiro: a rua Pires de Almeida, em Laranjeiras. Seu principal objetivo é verificar a aplicabilidade e a utilidade da observação incorporada na avaliação de um lugar urbano e na identificação dos elementos, índices e fatores geradores desta qualidade. Em complemento, são explorados percursos ou passeios à deriva de observadores sem conhecimento teórico-contextual prévio do lugar, e de relatos de experiências vivenciadas por observadores que já possuam uma vivência do lugar impregnada de afetos e significados. Os resultados evidenciam a riqueza dos relatos que incorporem os sentimentos e os afetos produzidos na interação entre os observadores, os usuários e o ambiente observado.

\section{Palavras-chave: Cognição, projeto, lugar, observação incorporada.}

\begin{abstract}
Pires de Almeida Street: Embodied Observation of a Particular Public Space - This article is part of the research "Cognition and Place Design": application of the enactive approach in performance evaluation of urban places. It intends to incorporate the concepts of enactive cognition proposed by Varela, Thompson and Rosch and of empathy, proposed by Thompson, to the work of Tuan, Norberg-Schulz, Lynch, Cullen, in an embodied observation carried out in a place of recognized quality in Rio de Janeiro: Pires de Almeida Street, in Laranjeiras. The main objective is to verify the applicability and the utility of embodied observation in the evaluation of an urban place and in the identification of elements, indexes and factors that generate its quality. In complement to the embodied observation, aimless walks and wanderings were carried out, by observers without prior theoretical-contextual knowledge of the place, and also the experiences by observers that already possess an experience of the place impregnated of affections and meanings. The results show up the richness of the reports that incorporate the feelings and the affections produced in the interaction among the observers, the users and the environment.
\end{abstract}

Key words: Cognition, project, place, embodied observation. 


\section{Introdução}

Este trabalho apresenta uma transformação na atitude do observador em trabalhos de investigação do lugar, em desenvolvimento pelo grupo Projeto e Qualidade do Lugar (ProLUGAR)' do PROARQ-FAU/UFRJ na pesquisa Cognição e Projeto do Lugar: aplicação do enfoque enactivo na avaliação de desempenho de lugares urbanos. Esta transformação na atitude do pesquisador/ observador em sua relação com o ambiente a ser observado, pressupõe a incorporação da sua experiência ao processo de observação, de modo recorrente, recíproco, interativo e indissociável. Com base na abordagem atuacionista da cognição proposta por Varela, Thompson e Rosch (2003) pretendemos comprovar a hipótese de que a incorporação da cognição experiencial ${ }^{2}$ contribui para qualificar e ampliar a compreensão do caráter e da qualidade do lugar.

Como objeto de estudo escolhemos a rua Pires de Almeida, em Laranjeiras (Figura 1), em função de sua escala, de ser um dos quatro estudos de caso da pesquisa Desenho Urbano e Qualidade do Lugar"3 que originou o presente estudo, e pelos seus atrativos reconhecidos e apreciados pelos moradores e usuários, que se refletem no valor de comercialização no mercado imobiliário da cidade do Rio de Janeiro.

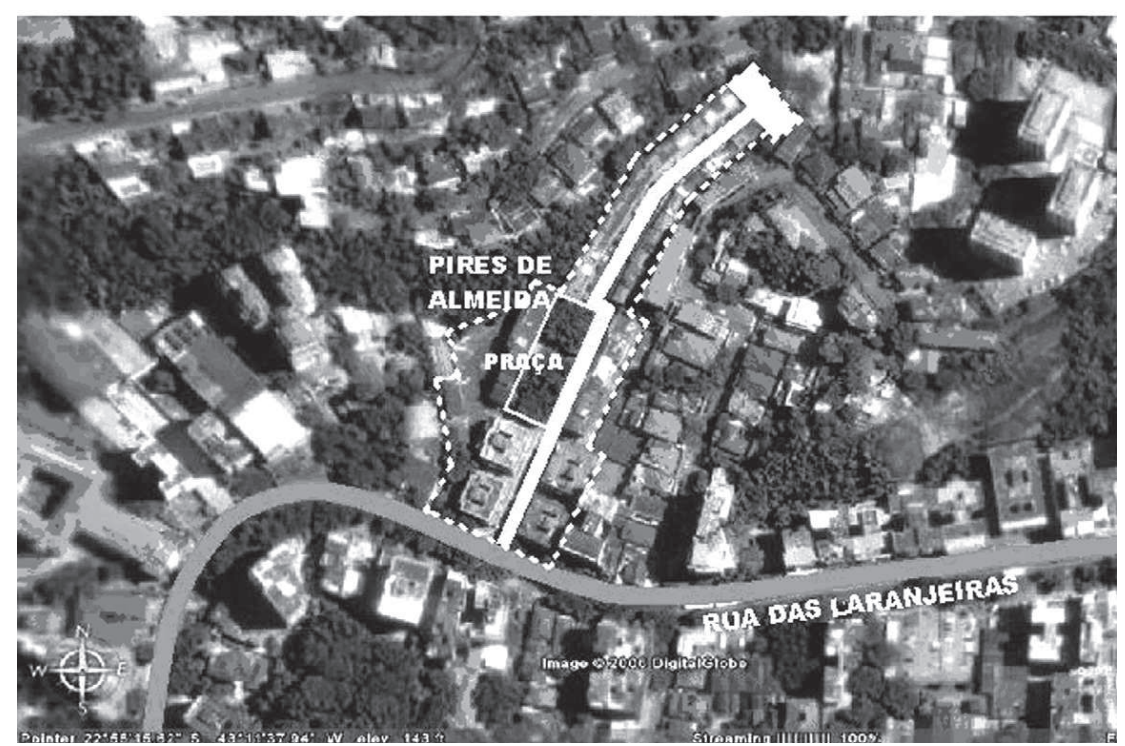

Figura 1: Localização do conjunto arquitetônico da rua Pires de Almeida

O quadro teórico-metodológico também se fundamenta nos conceitos de lugar e de geografia humana (TUAN, 1983; NORBERG-SCHULZ, 1979), de townscape (CULLEN, 1996) e nas dimensões de desempenho de Lynch (1961). Ao utilizarmos algumas das técnicas e instrumentos propostos para avaliação da qualidade do lugar definidas e validadas pela pesquisa acima citada, introduzimos esta nova postura - a de observador incorporado à ação.

O objetivo deste pré-teste ${ }^{4}$ é verificar a aplicabilidade e a utilidade da observação incorporada na avaliação de um lugar urbano e na identificação dos elementos, índices e fatores geradores de sua qualidade.

Como método complementar à observação incorporada, trabalharemos com:

(a) percursos ou passeios à deriva, que pressupõe que os primeiros contatos com o lugar devam ser realizados sem uma diretriz predeterminada e, preferencialmente, sem conhecimento teórico-contextual prévio do lugar, possibilitando ao observador pontuar e registrar suas primeiras impressões sem as preconcepções usuais e previsíveis apoiadas apenas no olhar técnico-arquitetônico e objetivo do pesquisador; o observador deve se deixar influenciar conscientemente pelos estímulos e sensações que, por sua vez produzirão emoções e respostas intersubjetivas com relação à experiência vivenciada; 
(b) relatos de experiências vivenciadas que, diferentemente dos passeios à deriva, mas complementares a eles, e com base no entendimento de que a realidade é sempre um argumento explicativo, e que "as explicações científicas não fazem referência a realidades independentes do observador" (MATURANA, 2002, p. 57), incorpora os relatos de observadores que possuam uma vivência do lugar impregnada de topofilia.

\section{Considerações Teórico-Metodológicas}

Segundo o conceito de topofilia (TUAN, 1980), as pessoas desenvolvem relações de atração e afeto ou de repulsa por um lugar, sentimento que está relacionado à memória e à imaginação. Segundo Tuan, a qualidade de um lugar está intrinsecamente ligada a um sentimento complexo, atemporal de difícil explicação em toda sua plenitude. O lugar significativo ou lugar psicológico, diferentemente do espaço geométrico, adquire definição - pela experiência adquirida - e significado - com seus símbolos, memórias e histórias vivenciadas. A orientação e a identificação do homem com o ambiente e sua conotação simbólica, conferem caráter ao lugar, que não se restringe a ser um simples abrigo, uma vez que atua como base existencial (NORBERG-SCHULZ, 1979).

O foco central é a experiência do homem no lugar; o modo como este lugar influencia a ação humana e o modo como a presença humana dá sentido e significado ao lugar. A percepção ou as capacidades sensório-motoras do homem - visão, audição, olfato, paladar, tato e seus movimentos e ações - são parte integrante do processo cognitivo e incluem a linguagem verbal e não-verbal. Inseridas em um contexto biológico, psicológico e cultural mais amplo, estas capacidades não podem existir sem a interação com o meio a ser experienciado; também o meio inexiste se não houver a presença do indivíduo para o experienciar. São aspectos bi-unívocos, indissociáveis e recíprocos da abordagem atuacionista da cognição proposta por Varela et al (2003).

Inspirado na abordagem atuacionista e consciente de que observador não pode pretender ter acesso a uma realidade independente dele próprio, o grupo ProLUGAR adotou a designação cognição experiencial para caracterizar as observações que incorporem as interações homemambiente em sua experiência de viver, enriquecendo e conferindo novo significado ao entendimento do lugar. Assim, é possível incorporar aos diversos instrumentos e técnicas normalmente aplicadas ao estudo e na avaliação do lugar uma atitude diferente do pesquisador, mais sensível e atenta em suas observações, relatos e análises.

Para facilitar o processo de interação desejado, resgatamos a terminologia conceitual de psicogeografia ${ }^{5}$ e de deriva ${ }^{6}$ proposta pela Internacional Situacionista, sociedade de ultra-esquerda fundada em 1958 por Guy Deborde (JACQUES, 2003). O método ou técnica da deriva pressupõe re-conhecer (ou re-descobrir) a cidade descontruindo as formas culturais tradicionais e impregnadas de pré-concepções, a partir de um caminhar pelo ambiente sem uma direção ou rumo pré-definido. Ao vagar como um flaneur ${ }^{7}$, o observador percebe o percurso e, à medida que este se abre e atrai o olhar, os sentidos e o caminhar, cria-se a situação e definem-se as impressões que emanam do ambiente e do percurso.

Para complementar este estudo utilizamos ainda a técnica de visão serial (CULLEN, 1996), de registrar em croquis ou fotografias o percurso realizado, identificando os principais elementos físicos que estruturam e identificam o lugar ${ }^{8}$ (LYNCH, 1960).

A técnica de percurso à deriva e a observação incorporada foram utilizadas nos levantamentos das características físicas da área e nos estudos das ações e comportamentos dos usuários no lugar. $\bigcirc$ envolvimento e a incorporação dos componentes da equipe de trabalho foram de fundamental importância, e suas anotações e registros das observações de campo foram incorporadas aos dados coletados para a análise cognitiva. 


\section{Sobre a Rua e a Praça Múcio Leitão}

O Jardim Sul América - atual Rua Pires de Almeida - é um conjunto de edifícios construído na década de 1920 pela empreiteira Monteiro Aranha para servir de vila dos funcionários da Cia. de Seguros Sul América, em terreno de quinze mil metros quadrados, no Bairro de Laranjeiras, Rio de Janeiro. Composto por 23 edifícios em estilo art déco, as 158 unidades de 1 a 4 quartos se destinavam a abrigar desde os diretores até os serventes da empresa.

A implantação e ocupação em três setores diferentes (Figuras 1 e 10) do lote refletia a hierarquia dos seus habitantes, assim como a distribuição interna dos edifícios: os quatro blocos mais próximos da rua das Laranjeiras, com seis pavimentos, dotados de sacadas de ferro, entradas com mármores, elevadores e apartamentos de quatro quartos com cerca de $180 \mathrm{~m}^{2}$, destinavam-se aos funcionários mais graduados. A Praça Múcio Leitão, com suas centenárias amendoeiras e playground abriga os edifícios de médio padrão, com quatro pavimentos e apartamentos de três quartos com cerca de $100 \mathrm{~m}^{2}$ (Figura 2). Na parte final da rua, em pequeno aclive, se enfileiram os edifícios mais simples, de três pavimentos e com apartamentos de dois e um quarto, tendo ao final da rua, um cul-de-sac. Em todos os edifícios, as dependências de empregados são localizadas no último pavimento e com acessos independentes pela entrada de serviço. Segundo o diretor da novela Suave Veneno, Ricardo Waddington, "O local é singular. A Pires de Almeida tem um quê de rua de bairro que se perdeu".

Em 1956, a empresa colocou os imóveis à venda, oferecendo-os aos locatários. Algumas famílias destes locatários continuam residindo na Pires de Almeida até hoje. Dentre seus moradores mais ilustres, destacam-se: Cândido Portinari, Ernesto Nazaré, Stanislaw Ponte Preta, Noel Nutels, Regis Bittencourt e Afonso Reidy. Segundo artigos publicados em periódicos locais, o lugar foi "moradia de artistas alternativos nos anos 70 e ponto de encontro dos Hell's Angels nos anos 80"

O conjunto arquitetônico representado pelos quatro primeiros blocos foi tombado pelo Município em 1986 ${ }^{10}$. Em 31/10/1991, a Lei 1784 criou sete subáreas de preservação na cidade - sendo uma delas, a Rua Pires de Almeida.

Em diversas reportagens e artigos de jornais locais e de bairro ${ }^{11}$ o título deixa clara a imagem positiva e o alto nível de valorização do lugar, tanto quanto aos aspectos materiais, quanto aos imateriais, sentimentais e subjetivos. Numa delas, o relato de uma jovem moradora:

"a tranqüilidade e a segurança da vila fazem com que crianças e jovens possam brincar e conversar até altas horas na pracinha, eleita o point do lugar. "Todos os meus amigos estão aqui. Todo mundo se conhece e eu posso ficar até uma, duas horas da madrugada na pracinha. Aqui é muito tranqüilo", diz Cristiane Martins, 17 anos". ${ }^{12}$

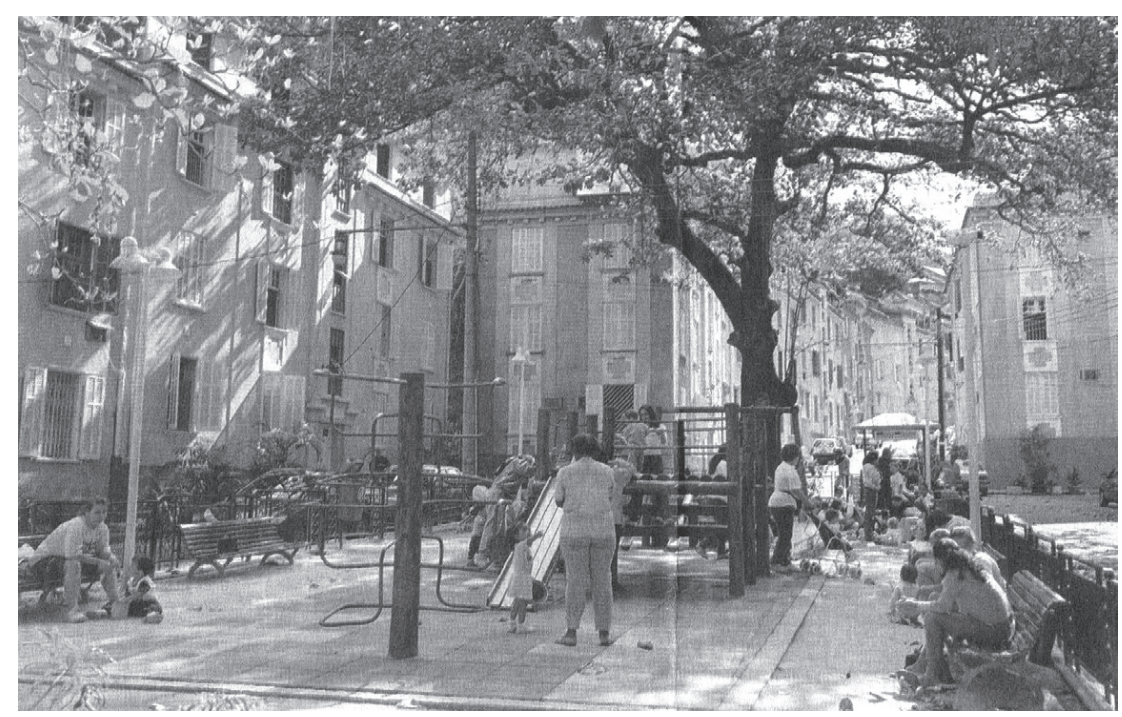

Figura 2: Foto da Praça

Mucio Leitão

Fonte: O Globo, 06/08/2006 -

Caderno Morar Bem, p. 2 


\section{Olhares à deriva}

A seguir, apresentamos o relato dos estagiários da pesquisa após realização de percurso à deriva com a atitude de observação incorporada, em março de 2006, pela manhã, de 9:00 às 12:00 h. A importância destes relatos se dá porque, além da descrição objetiva, elas incluem as sensações, estímulos e emoções vivenciadas por eles no ambiente observado.

Na rua residencial com "ares" de condomínio particular, o tempo nublado influenciou a análise, principalmente quanto às sensações climáticas dos diversos pontos da rua. $\bigcirc$ sol só despontou no final da visita, porém, sua influência não alterou a avaliação do microclima de toda a extensão da rua.

Desde seu início, na esquina com a Rua das Laranjeiras, a rua - sem saída - é tranqüila e agradável, com pessoas entrando ou saindo calmamente, em contraste com a esquina, mais movimentada. Não percebemos correria ou tumulto; a única coisa "gritante" no início do percurso foi a quantidade de veículos circulando nos dois sentidos da Rua das Laranjeiras.

Ao longo do percurso percebemos três setores com aspectos distintos: no início a presença de uma guarita com cancela, para o controle de veículos, dá a impressão de ser um condomínio fechado (Figura 3). No primeiro setor, observamos que os edifícios são todos alinhados com a rua e têm cinco pavimentos com suas fachadas pintadas na cor branca e em cores em tons pastéis, janelas de madeira nas cores branca e verde, venezianas com abertura para o exterior. Estes atributos transmitem a sensação de estarmos entrando em uma cidade do interior relativamente antiga (Figura 4).

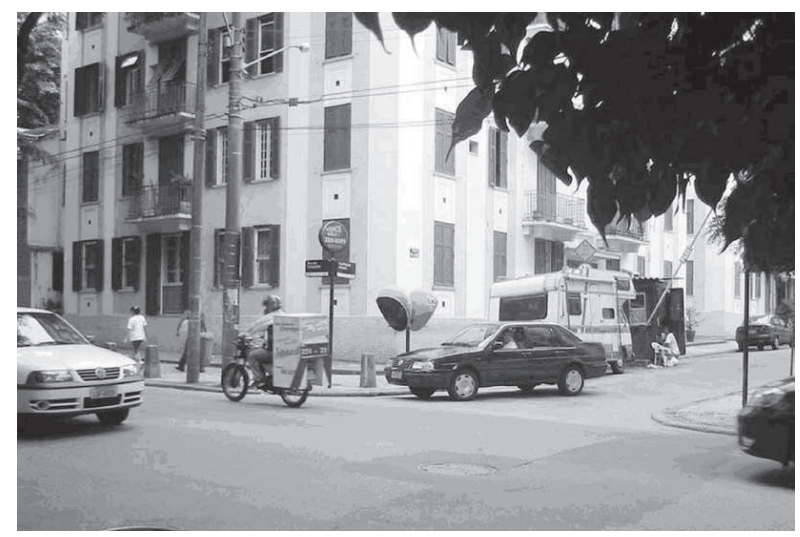

Figura 3: Esquina com a rua das Laranjeiras/ Edifício n. $7^{13}$

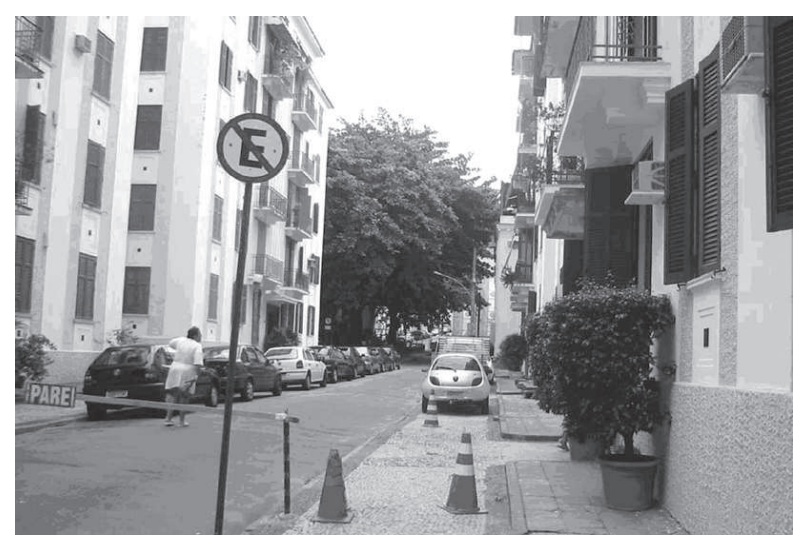

Figura 4: Vista junto ao Edifício n. 8

Avançando em direção ao interior, no segundo setor que contém a praça, observamos pessoas tranqüilas circulando - em geral mulheres guiando carrinhos de bebês, passeando com seus cães ou saindo para o trabalho. Suas expressões serenas demonstram o quanto o ambiente influencia seu cotidiano: rua arborizada, pouco barulho, boa iluminação e ventilação, microclima agradável e uma sensação de segurança. A Pires de Almeida é uma rua simpática e acolhedora.

Nosso caminhar foi despreocupado, sem a sensação de estarmos sendo vigiados, e fomos naturalmente atraídos pelo silêncio convidativo da pracinha e impelidos a nos afastarmos da movimentada esquina com a Rua das Laranjeiras. Apesar do tom tranqüilo, foi possível ouvir a conversa das pessoas, o ruído de panelas no interior dos apartamentos e o barulho familiar dos balanços da pracinha. A única perturbação ao "silencioso barulho" do lugar foi provocada por um avião que sobrevoou o bairro.

Ao cruzar com os pedestres, e em função da tranqüilidade de todos em seu caminhar, foi possível estabelecer um "diálogo" imediato ao cruzarmos nossos olhares. 
Na medida em que nos aproximamos da praça o ambiente se tornou cada vez mais aconchegante e calmo; com o frescor da manhã e da sombra das amendoeiras, as crianças brincavam alegres. Além dos pequeninos, mães e idosos conversavam entre si e com os vizinhos que, de suas janelas e sacadas, também animavam o ambiente.A praça é protegida com uma grade de ferro baixa que impede a entrada de cachorros. A maior parte das crianças brincava solta e livre, sem o risco de contato com os animais e seus dejetos. Suas vozes e gritos, ao reverberarem nas paredes dos edifícios que circundam a praça, produzem uma agradável paisagem sonora. $\bigcirc$ ar fresco sob a copa das árvores torna o ambiente adequado para caminhar e conversar. Não notamos a presença de odores desagradáveis; a sensação de "ar limpo" é acentuada, talvez devido à quantidade de árvores na praça (Figuras 2 e 5).

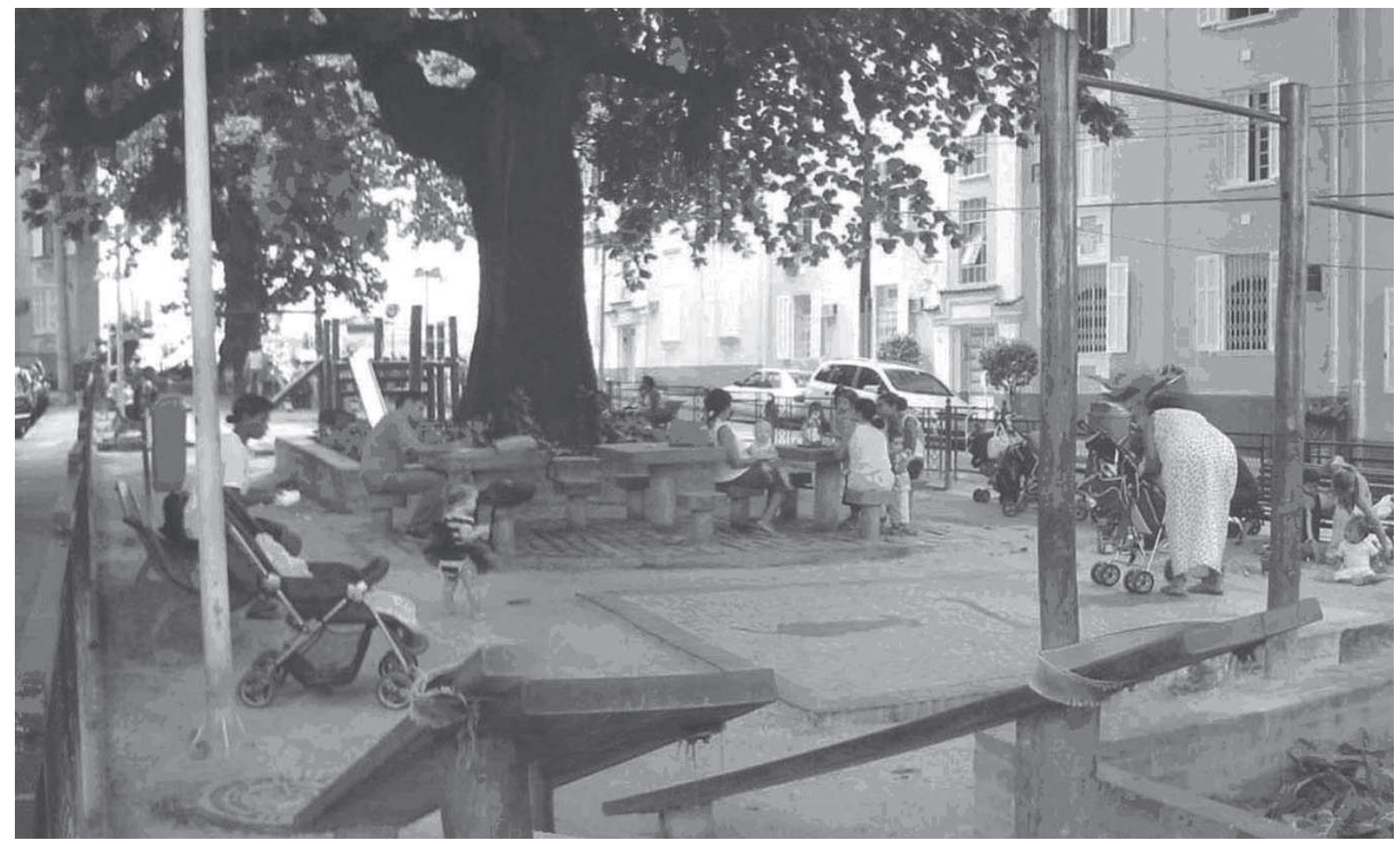

Figura 5: Praça Mucio Leitão, amplamente usada todos os dias para o lazer infantil

Continuando o percurso em suave aclive, no terceiro setor - após a praça - o ambiente se torna silencioso e o sol começa a despontar tornando aquele ambiente diferente do anterior. Apesar da mudança no micro-clima, o "ar" de ambiente bem cuidado e residencial não se alterou: havia jarros de plantas sobre a calçada, que parecia não ser usada para caminhar. As pessoas cumprimentavam-se e transitavam tranqüilas pela rua, dividindo o espaço com os poucos veículos que, eventualmente, passavam.

O silêncio foi quebrado vez por outra por vozes saídas do interior de algum apartamento. Aparentemente, a privacidade acústica é comprometida, pois foi possível ouvir claramente discussões entre um casal e entre uma filha e sua mãe. Como a parte final ("popular") da rua não é arborizada, caminhamos sob o sol, que esquentava com o passar do tempo.

Este trecho em aclive e sem saída se torna mais deserto e o ambiente, gradualmente, mais "frio": menos pessoas circulando, muita alvenaria e nenhuma vegetação (Figuras 6 e 7), presente apenas no final do percurso. Um muro de arrimo em pedra-de-mão contornando o cul-de-sac provocou incômodo visual (Figura 8). O muro "oprime" a quadra de futebol de salão do cul-de-sac que, durante a semana é utilizada como estacionamento e, nos finais de semana, para animadas partidas, jogos de pingue-pongue e sessões de skate; de lá é possível avistar a imagem do Cristo Redentor, enquadrada pelos edifícios (Figura 9). 


\section{Relatos de experiências vivenciadas}

Relato A - "conheço a rua Pires de Almeida desde 1958, quando tinha sete anos de idade, quando passava as férias de julho no edifício número 15, na casa de meus tios. Já no primeiro contato, fiquei fascinado com a pracinha, com as garagens do lado sul e com o marcador dos andares do elevador, um ponteiro e números de bronze que girava como um relógio. Passei três férias de julho neste apartamento, onde podia ver televisão - ainda inexistente no Rio Grande do Sul - e ler as revistinhas compradas na banca da esquina - outra novidade para mim. Nesta época, sem o acesso ao túnel Rebouças, a rua das Laranjeiras era bem mais tranqüila e bucólica, com seus bondes e lotações.

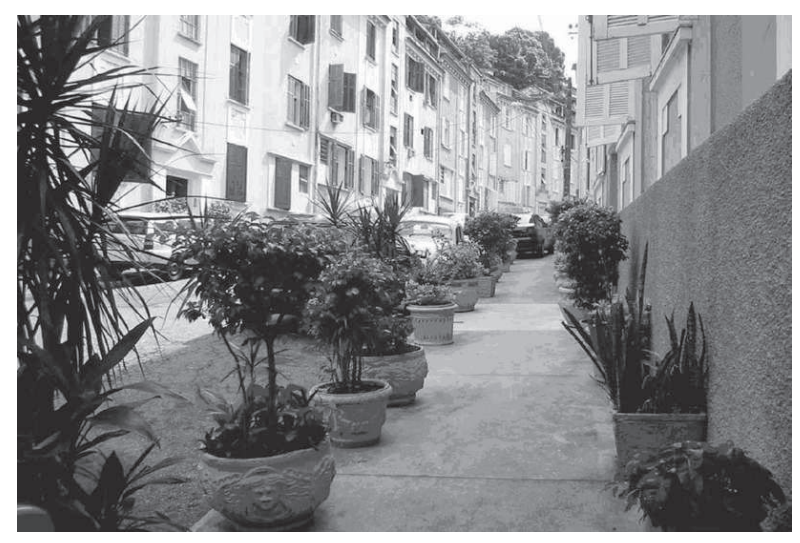

Figura 6: Início do "setor popular" do conjunto

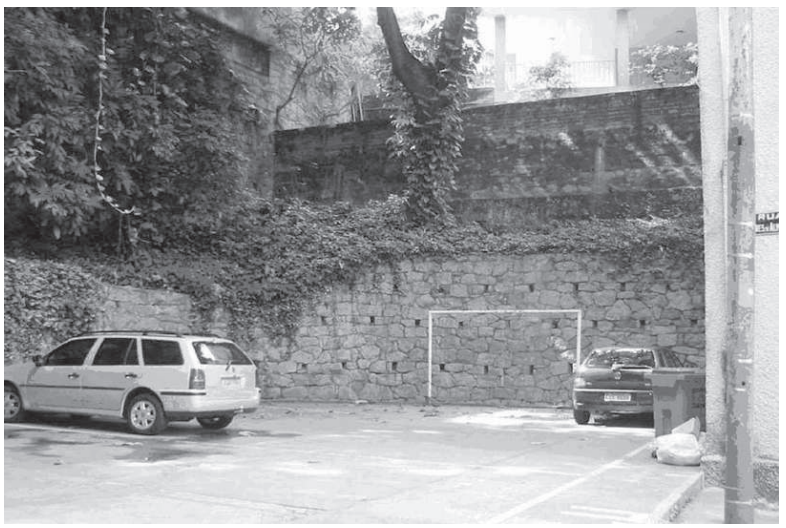

Figura 8: Cul-de-sac no final da rua

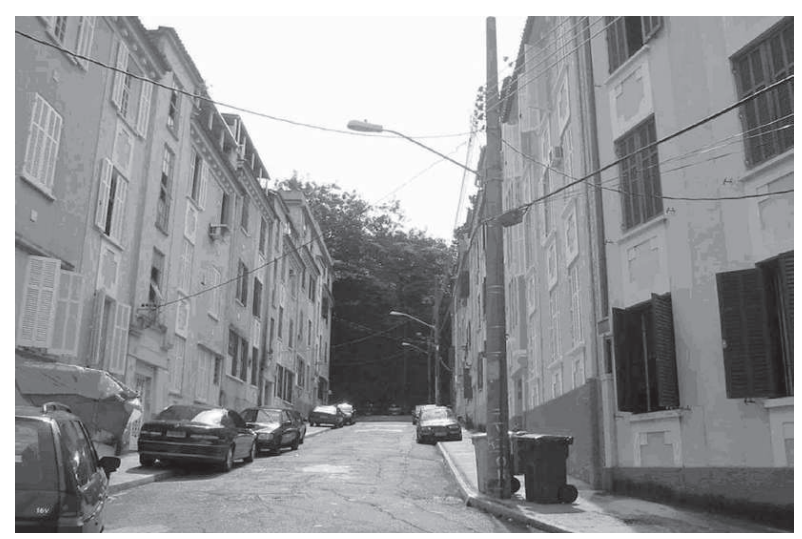

Figura 7: "Setor popular" com o cul-de-sac sob a densa arborização

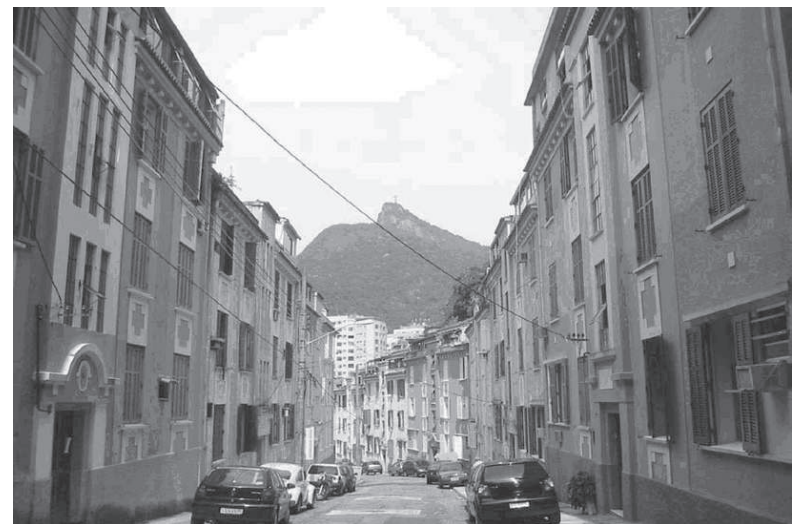

Figura 9: Vista da rua a partir do cul-de-sac

Em 1972, retornei à Pires de Almeida, onde residi até meados de 1974 com meus tios. Meu quarto, nos fundos, com vista para o Corcovado e o edifício Águas Férreas, transformou-se em um mundo novo de descobertas. Nesta época, uma das coisas mais pitorescas do lugar era o 'Cuco', um senhor gentil e bem-humorado que, a partir das 21:30 horas, invariavelmente abria sua janela de tempos e tempos e, delicadamente, lembrava aos jovens que conversavam animadamente na pracinha: 'são nove e meia!' ... 'são dez horas!' Também me encantava o barulho das folhas das amendoeiras da praça, o canto dos passarinhos e os micos.

As janelas de madeira com venezianas permitiam (e continuam permitindo) ouvir o farfalhar das folhas e sentir o cheiro de terra durante as chuvas e, nos dias e noites sem chuva, curtir a sonodiversidade dos adolescentes, as brincadeiras de crianças e os latidos esganiçados dos cachorros... tudo isto a menos de 50 metros da rua das Laranjeiras, com seu intenso tráfego. Um recanto bucólico em plena grande cidade, coisa comum nesta cidade ainda maravilhosa.

Outros pontos que me atraíam (e continuam atraindo) na rua e no apartamento: a sensação de segurança a qualquer hora do dia ou da noite - em seus quase oitenta anos de existência, nunca 
houve um assalto ou roubo na rua - e a luminosidade das janelas em todos os compartimentos, inclusive no corredor.

Após trinta anos, comprei o apartamento de meus tios, que anteriormente abrigou Afonso Eduardo Reidy. Curiosamente, em meio ao medo que assola os cariocas em geral, a pracinha segue congregando crianças, acompanhantes e cachorros durante o dia e adolescentes, em animados e descontraídos grupos à noite. A festa de São João é um capítulo à parte, com a rua decorada com bandeirinhas e três dias ininterruptos de animada festa com barracas de comidas típicas e música ao vivo, lembrando as festas de minha infância. O difícil, nesta nova experiência de vida, é encontrar um bom motivo para sair de casa ..."

Relato B "nasci e fui criada no interior de Minas, assim valorizo muito as edificações horizontais, os espaços livres de encontro e lazer e a relação do pedestre e morador com a rua, enfim, uma relação de espaço que só imaginava possível no interior e talvez antigamente quando o tempo não passava tão depressa.

Ao mudar para a Pires de Almeida encontrei um pouco do interior no Rio de Janeiro. Ao cruzar a guarita a sensação é a de estar entrando em outra cidade, em outra época. Os edifícios - um show a parte, com sua arquitetura art déco, a altura proporcional à largura da rua - causam um conforto visual difícil de se encontrar em áreas centrais e valorizadas como esta. Os apartamentos amplos, a vista privilegiada da Praça e do Corcovado e o silêncio, são fatores que fazem deste um ambiente especial e realmente encantador.

Outro fato peculiar da rua - similar a cidades do interior - é o hábito das pessoas observarem pela janela o que se passa na rua e na praça. Às vezes ao chegar ou sair de casa tinha a nítida sensação de estar sendo vigiada. Considero este procedimento o melhor e o pior do lugar: meIhor pela segurança que proporciona. Conforme Jane Jacobs (1961), a melhor forma de se ter segurança é a visibilidade. Mas, por outro lado, o pior é a sensação de estar sendo controlado o tempo todo. Existe a segurança, mas não existe a privacidade.

Enfim, minha curta experiência como moradora, apenas dois meses, foi suficiente para me apaixonar pelo local e fazer planos de, quem sabe um dia, voltar a morar lá, conciliando as vantagens de se morar em uma cidade maravilhosa e cheia de atrações e ao mesmo tempo conviver com a atmosfera de interior, a segurança, o sossego e o ar puro."

\section{Análises dos relatos}

Os relatos e depoimentos apresentados evidenciam tanto aspectos físicos e objetivos observados e vivenciados no lugar, quanto impressões mais subjetivas, impregnadas de emoções e de memória, ricas em significados. Com a observação incorporada, estes aspectos e impressões são agregados à análise técnica do arquiteto e urbanista baseada em conceitos consolidados de avaliação de desempenho urbano.

Dos elementos estruturadores da imagem mental ${ }^{14}(\mathrm{LYNCH}, 1960)$, identificamos, pelos relatos e pela análise da visão serial, três setores (Figura 10): o setor inicial com os edifícios mais sofisticados e próximos à Rua das Laranjeiras, o setor intermediário que contempla a pracinha e os edifícios em torno dela e o setor "popular", ao final da rua em aclive formado pelo alinhamento de edifícios. A disposição dos edifícios, predominantemente em blocos geminados com 4 a 6 pavimentos, mansardas nos telhados e sacadas nas fachadas frontais, cria uma ambiência que remete à cidade tradicional, especialmente pela praça, principal marco do lugar e ponto nodal de circulação e congregação comunitária.

Como limites, os edifícios criam um recinto retangular conformado pela rua e pela praça. Este fechamento configura um espaço protegido e facilmente vigiado pelos moradores que de qualquer ponto do espaço público ou de suas janelas possuem ampla visão do todo. A escala e 
as proporções da praça e a largura das ruas em relação à altura dos edifícios são outros fortes componentes. O alcance visual, devido às dimensões da pracinha e da rua, é adequado para que seja possível perceber as feições - e as intenções - de qualquer pessoa ou animal que se aproxime ou que esteja na praça, e configuram um espaço defensivo.
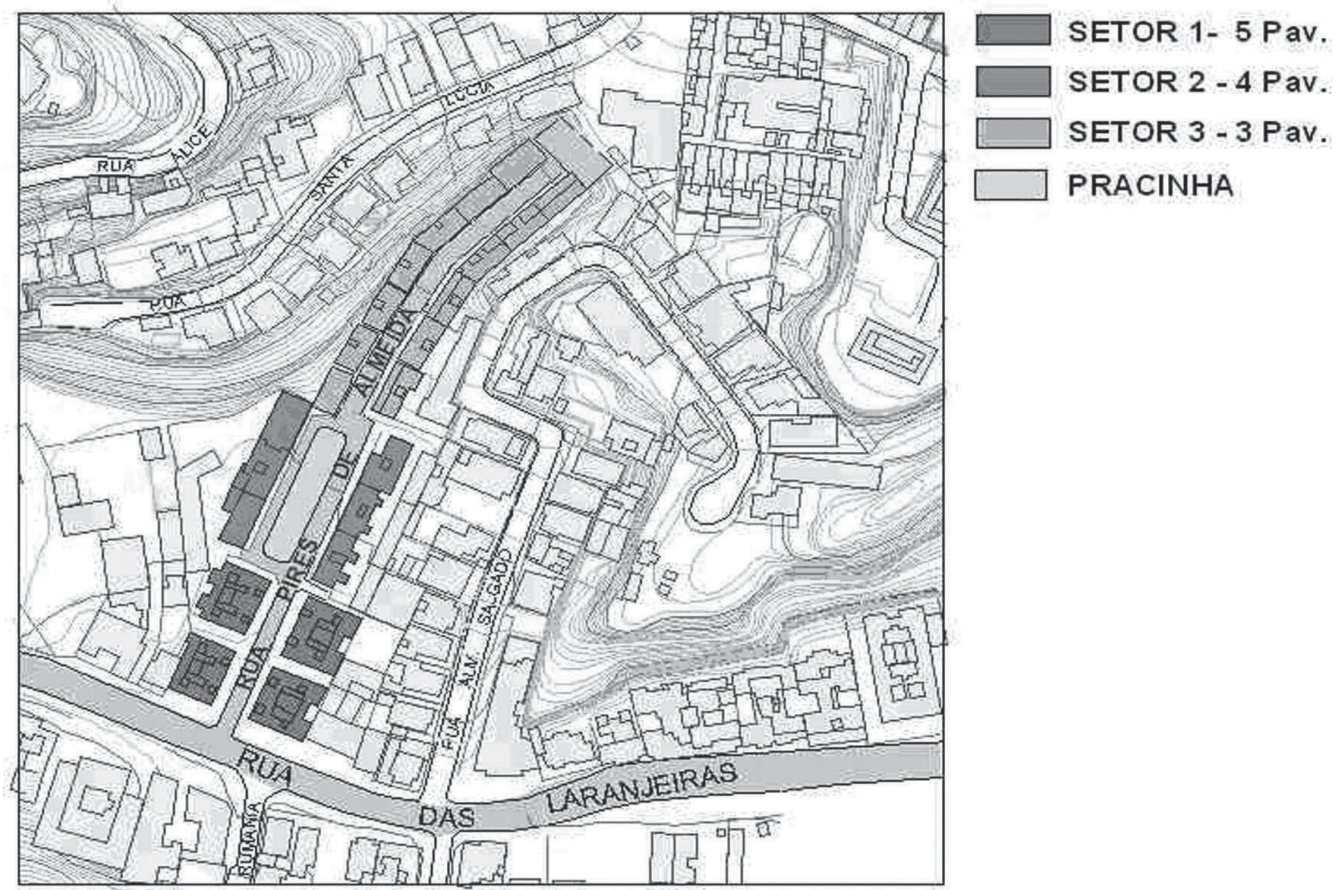

Figura 10: Situação com indicação dos três setores identificados na área

A reconhecida sensação de segurança, confirmada pela inexistência de roubos e assaltos, decorrente do partido de implantação, estranhamente tem sido pouco estudada como alternativa às grades e muros da segregação tão em moda na maior parte da cidade e considerados elementos indispensáveis para a segurança dos moradores de qualquer edifício ou condomínio.

A existência de vasos de plantas ocupando as calçadas e a circulação de pessoas pela rua denota uma apropriação das primeiras como espaço semi-público, já que os edifícios do segundo treço da rua não possuem porteiros. A ligeira inflexão e o leve aclive no terceiro setor estimulam o olhar em busca de novas descobertas em um ambiente que vai se descortinando aos poucos e de forma orgânica ao caminhante.

A implantação dos edifícios, a separação dos acessos social e de serviço e a disposição dos aposentos dos empregados no último pavimento demonstram a forte hierarquia e segregação da época. Hoje, os apartamentos são ocupados, em sua maioria, pela classe média, não tendo sido observada nas relações entre os moradores, a diferenciação hierárquica prevalente no passado. Alguns quartos de serviço tem sido alugados para estudantes ou pessoas solteiras, que o utilizam como moradia e/ou escritório ou ateliê, favorecendo e enriquecendo a diversidade populacional.

\section{Considerações finais}

A Pires de Almeida possui qualidades ambientais engendradas desde sua construção que atendem a vários dos critérios de dimensionamento da boa forma urbana (LYNCH, 1981), especialmente os de sentido, vitalidade e adequação. Com base nos percursos à deriva e nos depoimentos de moradores, é possível afirmar que seus usuários possuem boa estruturação mental e forte identificação com o lugar. Os estudos sobre a cognição experiencial realizados apenas confirmam a Rua Pires de Almeida como um lugar significativo e especial. 
A aplicação da observação incorporada para análise deste lugar urbano permitiu alcançamos dados subjetivos e qualitativos mais precisos e mais próximos da realidade local do que se tivéssemos nos apoiado apenas o olhar técnico e em dados quantitativos. A identificação dos elementos, índices e fatores geradores da qualidade do ambiente construído estão diretamente ligadas a relação intersubjetiva do observador com o lugar.

Podemos assim estabelecer, neste pré-teste, a validade da utilização da observação incorporada, e sugerimos que esta passe a permear todo o processo de pesquisa, desde seu início, sendo agregada aos métodos e instrumentos consolidados na avaliação do lugar.

\section{Notas}

(1) Grupo Projeto e Qualidade do Lugar (www.fau.ufri.br/prolugar), coordenado por Paulo Afonso Rheingantz.

(2) Designação proposta pelo grupo ProLUGAR para caracterizar a aplicação da abordagem atuacionista e da empatia nas APO's e avaliações de desempenho do ambiente construído.

(3) A pesquisa "Desenho Urbano e Qualidade do Lugar" - do (PROARQ-FAU-UFRJ), coordenação geral de Vicente del Rio e Paulo A. Rheingantz - prevê o estudo comparativo dos atributos físico-espaciais e cognitivos de quatro lugares de reconhecida qualidade no Rio de Janeiro: a Rua General Glicério e o Parque Guinle, que resultaram em dissertações de mestrado de Marcos Fávero e Denise de Alcantara, e a Rua Pires de Almeida e o Jardim Oceânico, em andamento.

(4) O objeto de estudo original da pesquisa é a cognição no Corredor Cultural do Rio de Janeiro.

(5) "Estuda os efeitos do meio geográfico, ordenado conscientemente ou não, e suas influências sobre o comportamento afetivo dos indivíduos." JACQUES, Paola B. Apologia da deriva. Casa da Palavra, 2003.

(6) "Modo de comportamento experimental, ligado às condições da sociedade urbana; técnica que consiste em passar apressado, por ambientes diversos. Designa, também e mais particularmente, a duração de um exercício contínuo dessa experiência." JACQUES, Paola B. Apologia da deriva. Casa da Palavra, 2003.

(7) Flâneur baudelairiano: o andarilho urbano, o curtidor do efêmero, o vagabundo consciente, o lascivo do instante (Henriques Neto, 2005, p. 94).

(8) Marcos, limites, setores, nós e percursos.

(9) Um pedacinho da Europa preservado no Rio. O Globo, 2 jan. 1997. Zona Sul, p. 13.

(10) Projeto de Lei n. 1258/85.

(11) Reportagens pesquisadas: Endereços Especiais, in Jornal do Brasil. Caderno Domingo, n. 1190, 21 fev. 1999, p. 24; Na fronteira entre Laranjeiras e Cosme Velho, um pedacinho da antiga Europa. O Globo, 10 maio 1998, Caderno Morar Bem, p. 2; O "ouvinte" das árvores. O Globo, 13 jul. 1991, O Meu Rio/Paulo Gracindo; Uma rua tranqüila, como em 1927. O Globo, 20 set. 1988. Bołafogo, p. 5; Longe da telinha, prevalece a tranqüilidade. O Globo, 23 maio 1999; Um pedacinho da Europa preservado na fronteira de Laranjeiras com Cosme Velho. $O$ Globo, 31 set 2001. Morar Bem, p. 2; Uma praça pública quase particular. O Globo, 6 ago. 2000, Morar Bem, p. 25.

(12) Vila Pires de Almeida: Marselha é aqui. Folha da Laranjeira, junho/2001, p. 8.

(13) Todas as fotografias tiradas em 28/03/2006 pelos autores.

(14) São cinco os elementos estruturadores da imagem mental definidos por Kevin Lynch: marcos, limites, setores, nós e percursos.

\section{Bibliografia}

ALCANTARA, D.; RHEINGANTZ, P. A cognição ambiental na avaliação da qualidade do lugar - Conceitos e métodos para o aprimoramento do desenho urbano. In: NUTAU'2004, São Paulo. Anais. São Paulo: NUTAU/USP, 2004. (CD-ROM).

CULLEN, Gordon. Paisagem urbana. Lisboa: Ed. 70, 1996.

JACQUES, Paola B. A apologia da deriva - Escritos situacionistas sobre a cidade. Rio de Janeiro: Casa da Palavra, 2003.

LYNCH, Kevin. The image of the city. Cambridge MA: MIT Press, 1960.

A theory of good city form. Cambridge: MIT Press, 1981.

MATURANA, Humberto. Cognição, ciência e vida cotidiana. Belo Horizonte: Editora da UFMG, 2001. 
NORBERG-SCHULZ, C. Genius Loci: Towards a phenomenology of architecture. Londres: Academy Press, 1979.

RHEINGANTZ, Paulo A. De corpo presente - Sobre o papel do observador e a circularidade de suas interações com o ambiente construído. In: NUTAU'2004, São Paulo. Anais. São Paulo: NUTAU/USP, 2004. (CD-ROM)

THOMPSON, Evan. Human Consciousness: From Intersubjectivity to Interbeing. Disponível em: <www.york.ca/evant> Acesso em: março de 2005.

TUAN, Yi-Fu. Espaço e lugar - A perspectiva da experiência. São Paulo: Difel, 1983.

VARELA, Francisco; THOMPSON, Evan; ROSCH, Eleanor. A mente incorporada - Ciências cognitivas e experiência humana. Porto Alegre: Artmed, 2003. 